\title{
EFNEP: 25 years' worth of sound advice
}

I

'or the last 25 years, the

Expanded Food and Nutrition Education Program (EFNEP) has been dispensing advice ranging from the four basic food groups to how to build a healthier taco.

The UC Cooperative Extension program, which marks its 25 th anniversary this year, is more than just a nutrition education program. It's aimed at improving the health and well-being of lowincome Californians, said Extension Specialist Amy Joy, who has been with the program for 15 years.

"Eating is not just about food. It also is an important social and family event. It is a way to bring people together. Our program goal is to help people help themselves. By

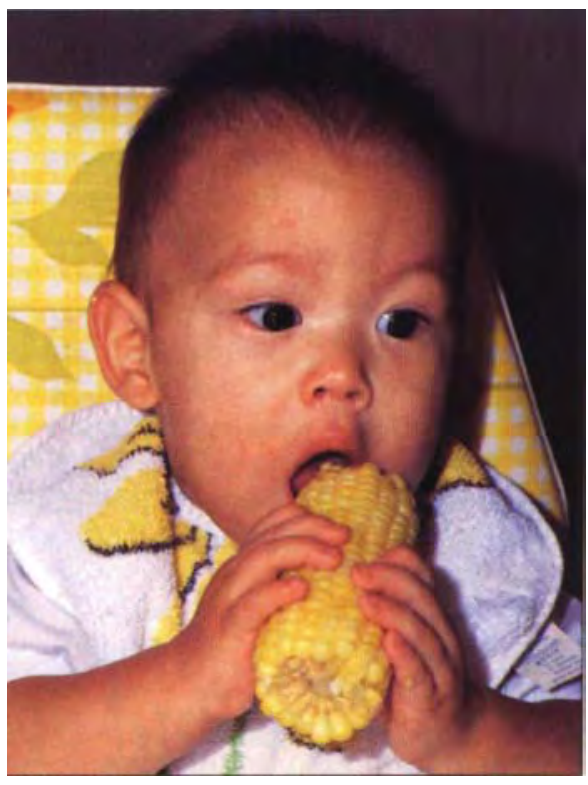

Cutting back on fats and sugar and eating more fruits and vegetables is one aim of the EFNEP program.

safely handle and store foods; and how to stretch a food budget by comparison shopping and using coupons.

"Our aim is to offer ways to improve nutrition by reducing cost, fat and salt in the diet. We always offer recommendations based on the cultural and ethnic traditions of the families we work with," Joy said. A healthy taco, for instance, has less meat and more vegetables.

The program recently conducted an evaluation to see how effective EFNEP is in increasing consumption of healthy foods. The study examined 650 families, half of whom were participating in EFNEP programs. It found that those families who had EFNEP training had better learning about nutrition and a healthy diet, people have more options and opportunities to improve their own and their families'

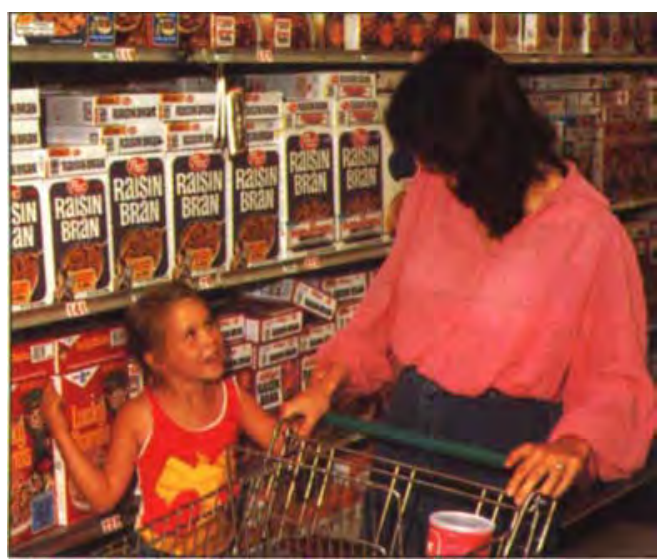

well-being," she said.

EFNEP, as it is informally known, started in 1968 as a pilot project using federal funds to provide nutrition education to low-income Americans. The California program receives $\$ 3.1$ million a year from the federal government, Joy said. This year, that money went to provide nutrition education for 12,500 Californians, all with monthly incomes of under $\$ 1,000$.

Groups of EFNEP par-

With EFNEP, families learn how to use coupons and comparison shopping to buy healthy foods and save money.

\section{ticipants meet six to eight}

times. Lessons are provided by paraprofessionals trained in the program, most of them coming from the same community. The lessons focus on the nutrition basics - such as the four food groups, and how to incorporate them into a diet. They also include information about how to prepare healthier foods by cutting back on fats, sugar and salt, and increasing fruits and vegetables; how to diets and ate significantly greater amounts of fruit vegetables and dairy products.

But the benefits of EFNEP are not limited to nutrition, Joy noted. Some participants are recent immigrants, who may not speak the language, or know how to provide a healthy diet for their families on a limited income in a new country.

The EFNEP staff may help people determine their eligibility for such programs as food stamps. It also performs a worthwhile goal by bringing people together. In some cases, those relationships continue after the EFNEP program has ended, with people forming buying clubs, baby-sitting cooperatives, and lifelong friendships.

The 25th year of the EFNEP program comes at a time when more and more Americans are going hungry. Though the program cannot actually put food on the table, it can help Californians by teaching them ways to stretch their food budget and still get adequate nutrition, Joy said. In 1989, she recalled, Congressman Leon Panetta of California called EFNEP "not just good for people in terms of good nutrition information; it is a good investment in the future."

"We will continue to offer assistance to all lowincome families, especially those with the most needs," Joy said. 